\title{
Solitary Nodular Goiter: Role of Ultrasonography in Fine-Needle Aspiration Cytology Diagnosis
}

\author{
Dilip K. Das $^{a}$ Chandra S. Pant $^{c}$ Krishan L. Chachra $^{a}$ \\ Ashish K. Mandal $^{b}$ Rajan Kumar ${ }^{b}$ Saroj K. Ganguly ${ }^{c}$ \\ Suresh Bhambhani ${ }^{a}$ Rajendra P. Tripathy ${ }^{c}$ \\ anstitute of Cytology and Preventive Oncology (ICMR), and bMaulana Azad Medical College, \\ New Delhi, India; 'Institute of Nuclear Medicine and Allied Sciences, Delhi, India
}

\section{Key Words}

Thyroid · Ultrasonography · Solitary nodules $\cdot$ Fine-needle aspiration cytology

\begin{abstract}
Purpose: To assess the contribution of ultrasonography to the fine-needle aspiration cytology diagnosis of solitary nodular goiters (SNG). Methods: 759 cases of SNG detected by ultrasonography were subjected to fineneedle aspiration. The age of the patients ranged from 9 to 92 years with a median of 35 years. Male:female ratio was 135:624. May-Grünwald-Giemsa-stained smears were reviewed and the cytodiagnosis was correlated with clinical and ultrasonographic findings. Results: The right lobe of the thyroid was more frequently involved (52.3\% cases) by solitary nodules compared to the left lobe (33.9\% cases) and isthmus (13.8\% cases).
\end{abstract}

\begin{tabular}{ll}
\hline KARGER & (1) 1998 S. Karger AG, Basel \\
Fax +4161306 1234 $34-7571 / 00 / 0093-0205 \$ 17.50 / 0$ \\
$\begin{array}{l}\text { E-Mail karger@karger.ch } \\
\text { www.karger.com }\end{array}$ & $\begin{array}{l}\text { Accessible online at: } \\
\text { www.karger.com/journals/mpp }\end{array}$
\end{tabular}

$27 \%$ of SNG cases missed at clinical examination could be detected because of ultrasonography. The frequency of solid echotexture in colloid goiter without cytologic evidence of cystic degeneration (60.3\%) was significantly higher than that observed in colloid goiter with cystic degeneration (32.6\%, p $<0.001)$. The difference of solid echotexture between hyperplastic nodules (55.4\%) and colloid goiter $(38.5 \%)$ was also statistically significant $(p<0.02)$. The frequency of solid echotexture and homogeneous hypoechoic pattern in neoplastic goiter (65.4 and $21.2 \%$, respectively) was significantly higher than that in nonneoplastic lesions (43.3 and 8.6\%, respectively, $\mathrm{p}<0.01)$. Conclusion: Ultrasonography, besides its use in the detection of solitary nodules and selection of appropriate areas for aspiration, correlated with cytological interpretation in the majority of cases. However, ultrasonography cannot replace 
cytologic diagnosis as the specificity and positive predictive values are not sufficiently accurate.

Copyright @ 2001 S. Karger AG, Basel

\section{Introduction}

Thyroid nodules comprise a gamut of disorders with widely differing biologic behavior and concealed among millions of thyroid nodules are only relatively few thyroid cancers [1]. The imputation that a clinically solitary nodule is a suspicious sign of carcinoma has been the cause of too many surgical procedures as well as subject of much controversy [2].

Fine-needle aspiration (FNA) biopsy has more than halved the number of operations in suspected thyroid cancer, by virtue of its being the most accurate and cost-effective method of evaluating a thyroid nodule [3]. However, some limitations of this technique include high inadequacy rate, lack of criteria to differentiate follicular adenoma from follicular carcinoma, and difficulties in diagnosing occult carcinoma [4]. Thyroid sonography acts as a complementary and supplementary technique to FNA cytology by allowing the whole gland and adjoining tissues to be examined, rather than just the dominanat nodule. Besides differentiating between solid and cystic lesions, and single and multiple lesions, ultrasonography enables accurate aspiration to be done under direct vision [5]. Although attempts have been made to define sonographic criteria for malignancy [6], the limitation of ultasonography in identifying different pathologies as suggested by Al-Sayer et al. [7] continues to remain and there are only a few published studies on ultrasound-guided/aided FNA cytology of thyroid nodules during the recent years [5, 8-14]. In the present study an attempt has been made to find out the contri- bution of ultrasonographic features to the FNA cytology diagnosis of solitary nodular goiters.

\section{Patients and Methods}

759 patients were found to have solitary nodular goiters by ultrasonography during the study period of 2 years (1987-1988). The overall age of the patients ranged from 9 to 92 years with a median of 35 years. Male:female ratio was 135:624. Clinically the patients presented with solitary nodules in 555 cases, multinodular goiter in 15 cases and diffuse goiter in 12 cases. In the remaining 177, the clinical categorization of goiter based on nodular vs. diffuse pattern was not made.

The ultrasound scanning was performed on patients in the supine position with a hyperextended neck. A 7.5-MHz short focus transducer attached to the arm of a static scanner (Technicare EDP 1200) was used. Transverse scans were performed starting from the suprasternal notch and longitudinal scans on either side of the midline at $0.5-\mathrm{cm}$ intervals. The site (left lobe, right lobe and isthmus) and size of the nodule, echotexture (cystic, mixed, solid), various solid echo patterns suchs as homogeneous (hypoechoic, isoechoic and hyperechoic) and heterogeneous, and types of degeneration (central, peripheral and combined, and regular/irregular) were noted. A $7.5-\mathrm{MHz}$ real-time transducer was used for guided FNA.

Smears were prepared directly from FNA material and/or from centrifuged deposits of aspirated fluid, and were air-dried and subjected to May-GrünwaldGiemsa staining. The FNA smears were reviewed by one of the investigators (D.K.D.) and the reviewed cytodiagnoses were correlated with the clinical and ultrasonographic findings. Histopathology reports available in 44 cases were correlated with the cytodiagnoses and ultrasonographic findings. The results were compared using chi-square test to determine the statistical significance.

\section{Results}

The reviewed FNA cytodiagnoses were colloid goiter in 371 cases, hyperplastic nodule (cellular adenomatoid nodule) in 69 cases, hyperplastic nodule/neoplastic goiter in 17 
Table 1. Clinical presentations of solitary nodular goiter as diagnosed by FNA cytology

\begin{tabular}{|c|c|c|c|c|c|c|c|c|}
\hline \multirow{2}{*}{$\begin{array}{l}\text { FNA cytology diagnosis } \\
\text { (reviewed) }\end{array}$} & \multirow[t]{2}{*}{ Cases } & \multirow{2}{*}{$\begin{array}{l}\text { Age } \\
\text { range } \\
\text { years }\end{array}$} & \multirow{2}{*}{$\begin{array}{l}\text { Median } \\
\text { age }\end{array}$} & \multirow{2}{*}{$\begin{array}{l}\text { Male: } \\
\text { female }\end{array}$} & \multicolumn{4}{|c|}{ Clinical diagnosis } \\
\hline & & & & & SN & MNG & $\begin{array}{l}\text { diffuse } \\
\text { goiter }\end{array}$ & NOS \\
\hline Colloid goiter & 371 & $9-92$ & 35.0 & $66: 305$ & 277 & 7 & 6 & 81 \\
\hline $\mathrm{HN}$ & 69 & $13-62$ & 32.0 & $13: 56$ & 51 & 2 & 1 & 15 \\
\hline HN/neoplastic goiter & 17 & $22-70$ & 35.0 & $2: 15$ & 13 & 0 & 0 & 4 \\
\hline Neoplastic goiter & 64 & $13-75$ & 32.5 & $12: 52$ & 47 & 3 & 3 & 11 \\
\hline Possible neoplastic goiter & 14 & $16-44$ & 34.0 & $0: 14$ & 8 & 0 & 1 & 5 \\
\hline Inflammatory goiter & 20 & $14-65$ & 35.0 & $4: 16$ & 10 & 1 & 0 & 9 \\
\hline Possible inflammatory goiter & 4 & $29-53$ & 36.5 & $0: 4$ & 3 & 0 & 0 & 1 \\
\hline Thyrotoxic goiter & 4 & $21-45$ & 35.0 & $1: 3$ & 3 & 0 & 0 & 1 \\
\hline Inadequate & 196 & $12-70$ & 37.0 & $37: 159$ & 143 & 2 & 1 & 50 \\
\hline Total & 759 & 9-92 & 35.0 & $135: 624$ & 555 & 15 & 12 & 177 \\
\hline
\end{tabular}

$\mathrm{SN}=$ Solitary nodule; $\mathrm{MNG}=$ multinodular goiter; $\mathrm{NOS}=$ not otherwise specified

cases, neoplastic goiter in 64 cases, possible neoplastic goiter in 14 cases, inflammatory goiter in 20 cases, possible inflammatory goiter in 4, thyrotoxic goiter in 4 and inadequate specimen in 196 cases.

The age distribution and sex ratio of the patients, and the clinical presentation in respect of nodularity vs. diffuse pattern in various types of goiter are shown in table 1 . The median age of most of the goiter types (colloid, inflammatory and thyrotoxic) was 35 years. The median age was slightly less in hyperplastic nodules (32 years) and neoplastic goiters (32.5 years). Only $555(73.1 \%)$ cases were clinically diagnosed as solitary nodules. This included $74.7 \%$ of colloid goiter, $73.9 \%$ of hyperplastic nodules (HN) and $73.4 \%$ of neoplastic goiters. A smaller number of inflammatory goiter cases (50\%) clinically presented as solitary nodules.

The site distribution of the solitary nodules and their echotexture are shown in table 2. The echopattern in the solid nodules is shown in table 3 . The nodule was situated in the right lobe in 292 cases, in the left lobe in 189 cases and in the isthmus in 77 cases. In 201 cases the precise site of the nodule in the thyroid could not be identified. The higher frequency of involvement of the right lobe was observed in all major cytologic types of goiters.

The echotexture was not specified in 69 cases. Of the remaining 690 cases, 327 (47.4\%) were solid, $294(42.6 \%)$ were mixed and 69 (10\%) were completely cystic. Amongst the solid nodules the echopattern was homogeneous in 138, heterogeneous in 63 and not specified in 126 . The solid homogeneous nodules were hypoechoic in $72(52.9 \%)$, isoechoic in $52(37.7 \%)$ and hyperechoic in $13(9.4 \%)$.

In colloid goiter mixed echotexture was observed in 182 cases, followed by solid (131 cases) and cystic texture (27 cases). While mixed texture (fig. 1a) was more common $(58.1 \%)$ in colloid goiter with cytologic evidence of cystic degeneration (fig. 1b), solid texture (fig. 1c) was more common (60.3\%) in colloid goiter without cytologic evidence of cystic degeneration (fig. 1d). The difference in 
Table 2. Ultrasonographic findings (echotexture) in solitary nodular goiter as diagnosed by FNA cytology

\begin{tabular}{|c|c|c|c|c|c|c|c|c|c|}
\hline \multirow[t]{2}{*}{ FNA cytology diagnosis (reviewed) } & \multirow[t]{2}{*}{ Cases } & \multicolumn{4}{|c|}{ Site of distribution } & \multicolumn{4}{|c|}{ Echotexture } \\
\hline & & $\begin{array}{l}\text { left } \\
\text { lobe }\end{array}$ & $\begin{array}{l}\text { right } \\
\text { lobe }\end{array}$ & isthmus & s NOS & cystic & mixed & solid & NOS \\
\hline Colloid goiter without cystic degeneration & 79 & 22 & 24 & 10 & 23 & 2 & 27 & 44 & 6 \\
\hline Colloid goiter with cystic degeneration & 292 & 60 & 122 & 30 & 80 & 25 & 155 & 87 & 25 \\
\hline $\mathrm{HN}$ & 69 & 20 & 32 & 4 & 13 & 1 & 28 & 36 & 4 \\
\hline $\mathrm{HN} /$ neoplastic goiter & 17 & 3 & 7 & 2 & 5 & 0 & 5 & 9 & 3 \\
\hline Neoplastic goiter & 64 & 20 & 25 & 6 & 13 & 1 & 17 & 34 & 12 \\
\hline Possible neoplastic goiter & 14 & 2 & 8 & 1 & 3 & 1 & 2 & 8 & 3 \\
\hline Inflammatory goiter & 20 & 3 & 6 & 3 & 8 & 1 & 9 & 7 & 3 \\
\hline Possible inflammatory goiter & 4 & 1 & 1 & 1 & 1 & 0 & 0 & 3 & 1 \\
\hline Thyrotoxic goiter & 4 & 2 & 1 & 1 & 0 & 0 & 1 & 2 & 1 \\
\hline Inadequate & 196 & 56 & 66 & 19 & 55 & 38 & 50 & 97 & 11 \\
\hline Total & 759 & 189 & 292 & 77 & 201 & 69 & 294 & 327 & 69 \\
\hline
\end{tabular}

NOS $=$ Not otherwise specified

Table 3. Solitary nodular goiter: correlation between cytodiagnosis and different solid echo patterns

\begin{tabular}{|c|c|c|c|c|c|c|c|}
\hline \multirow[t]{2}{*}{ FNA cytology diagnosis (reviewed) } & \multirow[t]{2}{*}{ Cases } & \multirow{2}{*}{$\begin{array}{l}\text { With solid } \\
\text { echo- } \\
\text { texture }\end{array}$} & \multicolumn{3}{|c|}{ Solid homogeneous } & \multicolumn{2}{|l|}{ Solid } \\
\hline & & & $\begin{array}{l}\text { hypo- } \\
\text { echoic }\end{array}$ & $\begin{array}{l}\text { iso- } \\
\text { echoic }\end{array}$ & $\begin{array}{l}\text { hyper- } \\
\text { echoic }\end{array}$ & $\begin{array}{l}\text { hetero- } \\
\text { geneous }\end{array}$ & NOS \\
\hline Colloid goiter without cystic degeneration & 79 & 44 & 8 & 10 & 2 & 6 & 18 \\
\hline Colloidgoiter with cystic degeneration & 292 & 87 & 16 & 11 & 4 & 24 & 32 \\
\hline $\mathrm{HN}$ & 69 & 36 & 8 & 9 & 1 & 5 & 13 \\
\hline HN/neoplastic goiter & 17 & 9 & 1 & 2 & 0 & 1 & 5 \\
\hline Neoplastic goiter & 64 & 34 & 11 & 7 & 1 & 3 & 12 \\
\hline Possible neoplastic goiter & 14 & 8 & 2 & 2 & 0 & 0 & 4 \\
\hline Inflammatory goiter & 20 & 7 & 4 & 1 & 0 & 1 & 1 \\
\hline Possible inflammatory goiter & 4 & 3 & 0 & 2 & 0 & 1 & 0 \\
\hline Thyrotoxic goiter & 4 & 2 & 0 & 0 & 0 & 1 & 1 \\
\hline Inadequate & 196 & 97 & 23 & 8 & 5 & 21 & 40 \\
\hline Total & 759 & 327 & 73 & 52 & 13 & 63 & 126 \\
\hline
\end{tabular}

NOS $=$ Not otherwise specified.

frequency of solid echotexture between the two groups was highly significant $(\mathrm{p}<0.001)$.

In $\mathrm{HN}$ and $\mathrm{HN} /$ neoplastic goiter cases (fig. 2) the solid echotexture was the most fre- quent type (55.4 and $64.3 \%$, respectively) followed by mixed texture (43.1 and 35.7\%, respectively). Cystic lesion was either absent or rare. The difference between $\mathrm{HN}$ and col- 

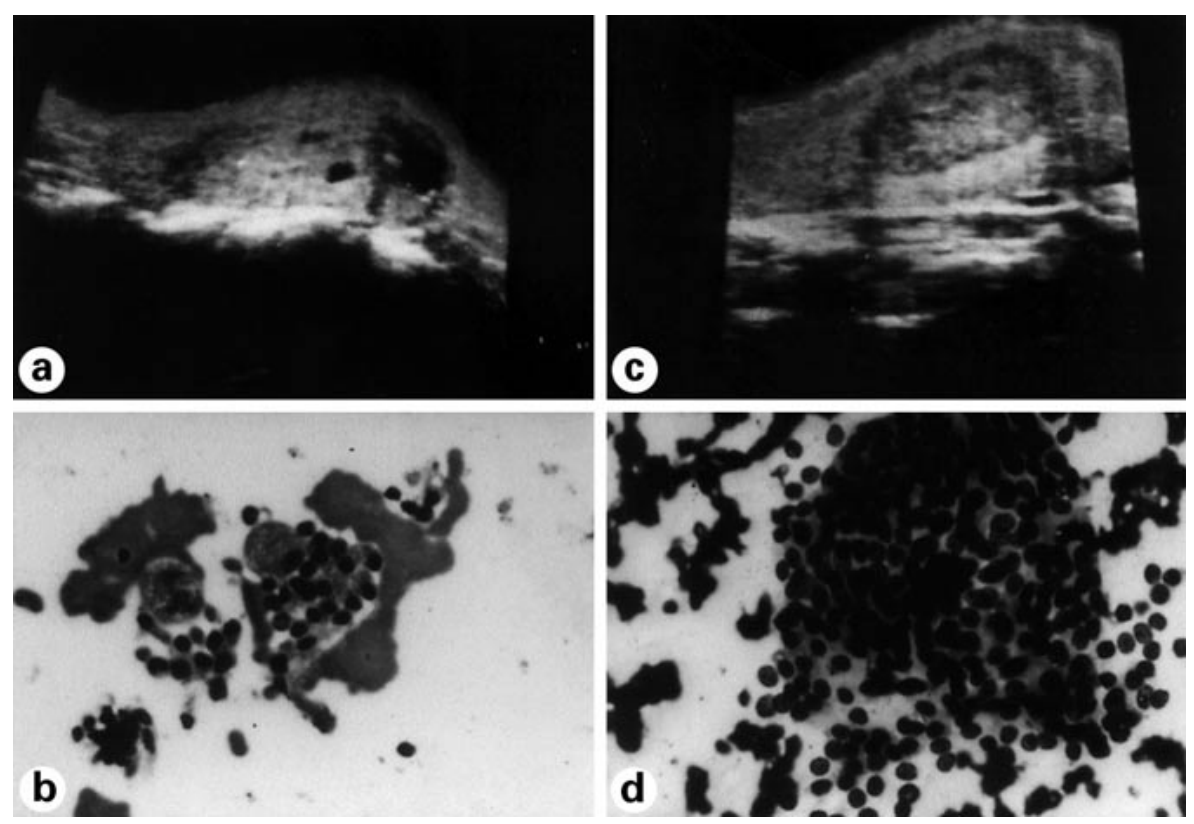

Fig. 1. a Longitudinal sonogram showing a mixed (right lobe) nodule with central and peripheral irregular degeneration. b Colloid goiter with cystic degeneration: benign follicular cells and cyst cells. FNA cytologic features of the case shown in a. May-Grünwald-
Giemsa. $\times 250$. c Longitudinal sonogram showing a well-defined solid solitary nodule. d Colloid goiter: benign follicular cells against a background film of colloid and blood. FNA cytologic features of the case shown in c. May-Grünwald-Giemsa. $\times 250$. loid goiter in respect of solid echotexture was statistically significant $(\mathrm{p}<0.02)$.

Amongst the noeplastic goiters solid echotexture was also more common (65.4\%) than mixed texture $(32.7 \%)$. Completely cystic echotexture was very rare $(1.9 \%)$. The frequency of solid echotexture in neoplastic goiters was significantly higher compared to that in nonneoplastic lesions $(43.3 \%, \mathrm{p}<0.01)$. The neoplastic goiters consisted of 20 follicular neoplasms, 22 usual papillary carcinomas, 10 cases of follicular variant of papillary carcinoma (FVPC), 7 Hürthle cell neoplasms, 2 medullary carcinomas and 3 miscellaneous malignancies. Follicular neoplasms, FVPC, Hürthle cell neoplasms and medullary carcinomas were overwhelmingly solid (fig. 3a, b). In the usual type of papillary carcinoma mixed echotexture (fig. 3c, d, e) was almost as common as solid texture. With respect to solid homogeneous hypoechoic pattern, the neoplastic goiters $(21.2 \%)$ differed significantly from the nonneoplastic lesions $(8.6 \%, \mathrm{p}<$ $0.01)$. There was a significant difference between neoplastic goiters and colloid goiter with respect to solid $(p<0.001)$ and mixed echotexture $(p<0.01)$, but no significant difference was observed between neoplasms and hyperplastic nodules with respect to echotextures.

Amongst inflammatory goiter cases, mixed echotexture was more common $(52.9 \%)$ followed by solid $(41.2 \%)$ and cystic texture (5.9\%). In the inflammatory goiters presenting as solid nodules, the hypoechoic pattern was very common (66.7\%). 

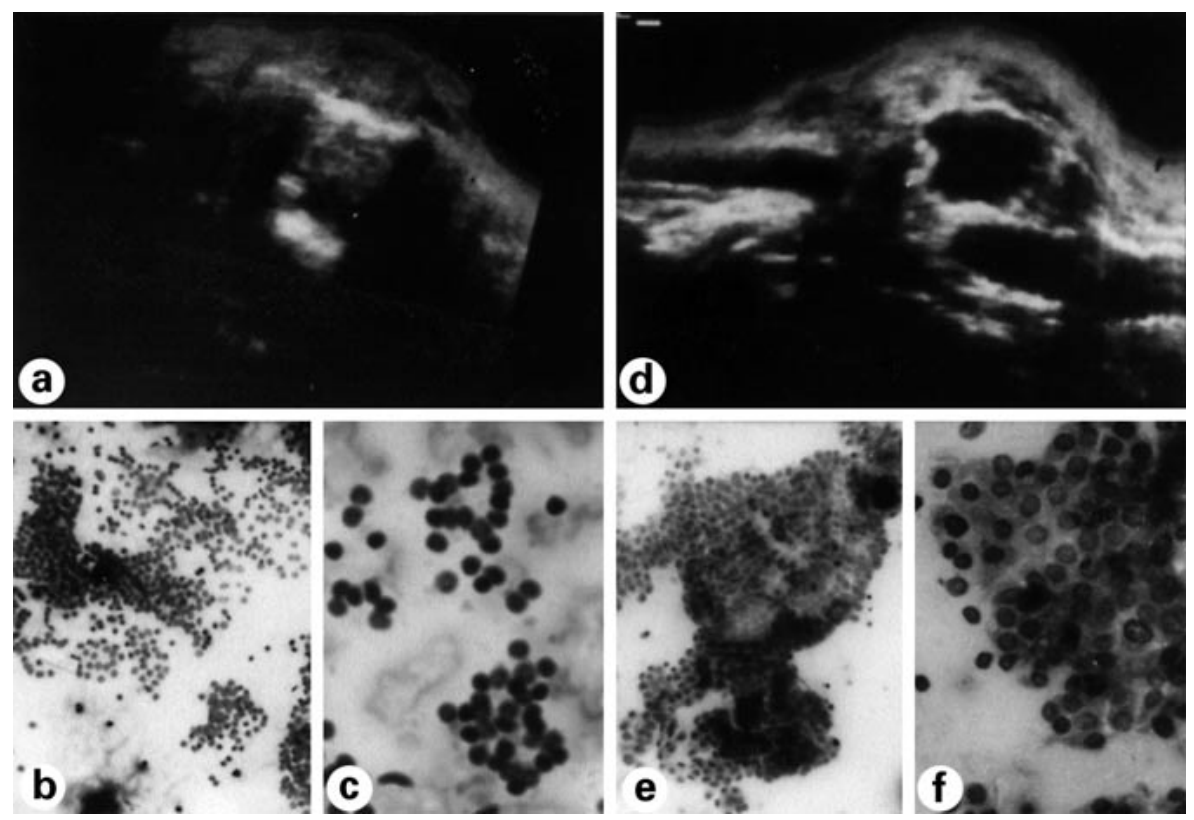

Fig. 2. a Transverse sonogram of a solid isthmic nodule. b Hyperplastic nodule/follicular neoplasm. Highly cellular smear shows sheets and groups of follicular cells. FNA cytology of the case shown in a. May-Grünwald-Giemsa. $\times 100$. c Higher magnification of the case shown in $\mathbf{b}$. Cells show microacinar formation. May-Grünwald-Giemsa. $\times 250$. d Transverse sonogram of a right lobe nodule showing mixed echopattern

Comparison of cytodiagnosis and ultrasonographic findings with histopathological diagnosis is shown in table 4 . The sensitivity and specificity of FNA cytology for the diagnosis of neoplastic goiter were 87.5 and 100\%, respectively, and those for carcinoma were 83.3 and $100 \%$, respectively. The overall diagnostic accuracy was $88.6 \%$. Of the 26 histologically diagnosed benign cases with specified echotexture cystic, mixed and solid lesions were observed in $2(7.7 \%), 12(46.2 \%)$ and $12(46.2 \%)$, respectively. The malignant cases showed mixed and solid texture in 60 and $40 \%$, respectively, but no cystic texture. (predominantly cystic) diagnosed as hyperplastic nodule by FNA cytology. e Hyperplastic nodule: highly cellular smear. FNA smear of the case shown in $\mathbf{d}$. May-Grünwald-Giemsa. $\times 100$. f Higher magnification of the case shown in $\mathbf{e}$. Sheets of benign follicular cells along with occasional mitotic figure. May-Grünwald-Giemsa. $\times 250$.

\section{Discussion}

Ultrasonography is a valuable tool in determining whether the nodule is solitary and acts as an objective indication of the size of the lesion during follow-up [10]. It helps to detect small and deep-seated nodules that cannot be palpated by the physician [12]. Ultrasound-guided FNA cytology not only helps in preoperative location of thyroid cancer but also plays a positive role in their postoperative follow-up [15-17]. By US-guided FNA cytology, Rosen et al. [12] were able to get cytologic information in $60 \%$ of patients 

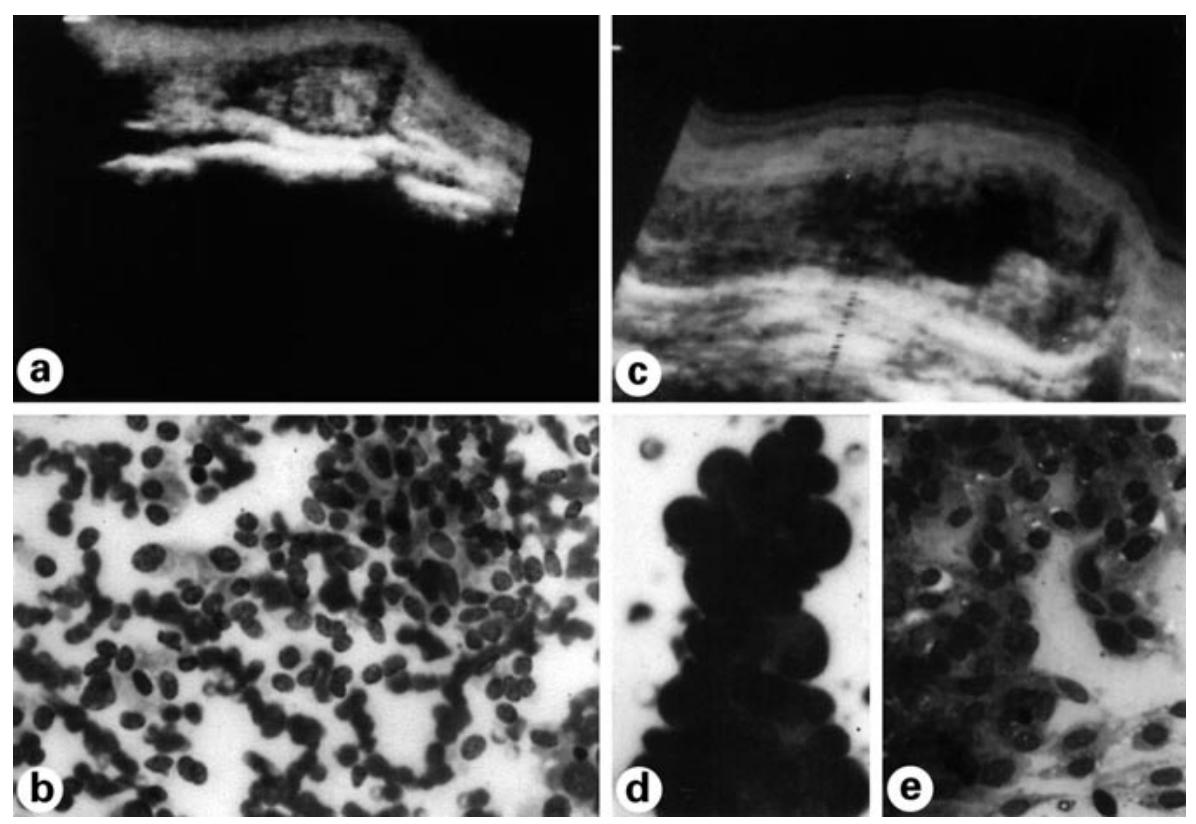

Fig. 3. a Longitudinal sonogram showing a solid nodule with peripheral hypoechoic pattern. Malignancy

roid showing a predominantly cystic pattern. d Papillary thyroid carcinoma: a compact papillary cluster of was suspected. b Medullary carcinoma thyroid: spindle-shaped, plasmacytoid and triangular cells. FNA smear from the case shown in a. May-GrünwaldGiemsa. $\times 250$. c Longitudinal sonogram of the thycells. FNA smear from the case shown in c. May-Grünwald-Giemsa. $\times 400$. e Same case as shown in $\mathbf{d}$. Small and monomorphic columnar cells. May-GrünwaldGiemsa. $\times 250$.

Table 4. Solitary nodular goiter: correlation of histopathological diagnosis with FNA cytodiagnosis and ultrasonographic features

\begin{tabular}{|c|c|c|c|c|c|c|c|c|c|c|}
\hline \multirow{2}{*}{$\begin{array}{l}\text { Histopathological } \\
\text { diagnosis }\end{array}$} & \multirow[t]{2}{*}{ Cases } & \multicolumn{5}{|c|}{ FNA cytology diagnosis (reviewed) } & \multicolumn{4}{|c|}{ Ultrasonographic features } \\
\hline & & $\begin{array}{l}\text { colloid } \\
\text { goiter }\end{array}$ & $\mathrm{HN}$ & $\begin{array}{l}\mathrm{HN} / \\
\text { neoplasm }\end{array}$ & FN & $\mathrm{Ca}$ & cystic & mixed & solid & NOS \\
\hline Colloid goiter & 25 & 23 & 1 & 1 & - & - & 2 & 11 & 10 & 2 \\
\hline $\mathrm{HN}$ & 2 & - & 1 & 1 & & - & - & - & 1 & 1 \\
\hline Follicular adenoma & 2 & - & - & - & 2 & - & - & 1 & 1 & - \\
\hline Carcinoma & 6 & 1 & - & - & - & 5 & - & 3 & 2 & 1 \\
\hline Total & $35^{\mathrm{a}}$ & 24 & 2 & 2 & 2 & 5 & 2 & 15 & 14 & 4 \\
\hline
\end{tabular}

$\mathrm{FN}=$ Follicular neoplasm $; \mathrm{Ca}=$ carcinoma $\mathrm{NOS}=$ not otherwise specified .

a 9 cases, in which FNA cytology diagnosis was inadequate, are not included in the table. Histopathological diagnoses were colloid goiter $(n=5)$, hyperplastic nodule $(n=1)$, follicular adenoma $(n=1)$ and carcinoma $(n=2)$ in these cases. 
in whom a diagnosis could not be established by orthodox (office) FNA biopsy, thus enhancing the diagnostic ability of the clinicians who could then recommend a treatment program with confidence.

In the present study, of the 759 ultrasonically diagnosed solitary nodules 555 (73.1\%) were diagnosed as such by clinical examination and 27 (3.6\%) were diagnosed as multinodular or diffuse goiter. In the remaining $177(23.3 \%)$ cases it was not possible to diagnose the exact type of thyroid lesion as regards its nodular vs. diffuse nature on clinical grounds. Thus, in about $27 \%$ cases ultrasonography was of use in detecting the solitary nodules which were not clinically evident. The higher frequency of involvement of the right lobe was an interesting observation in this study.

Ultrasonography categorizes nodules as solid, cystic or mixed with more than $90 \%$ of accuracy and is the best method for determining the volume of a nodule [18]. In our material it was possible to decide the echotexture in $90.9 \%$ of cases by ultrasonography. It was of help in selecting not only solitary nodules but specific areas inside the nodules for FNA. It is claimed that ultrasonography of the thyroid gland does not allow a reliable tissue diagnosis [19]. However, progress has been made in this direction during the recent years; with the availability of high resolution ultrasonography [20] and integration of B-mode and color Doppler ultrasonography [21], the sensitivity for diagnosis of thyroid lesions by ultrasonography has increased. In our study colloid goiter without cytologic evidence of cystic degeneration had a solid pattern in a significantly higher number of cases than in colloid goiter with cystic degeneration, indicating a good correlation between the ultrasonographic findings and cytopathological diagnosis.

According to Mazaferri [22] malignant lesions cannot be differentiated reliably by ul- trasonography. Jones et al. [10], however, interpreted solid or mixed solid/cystic structure as features suggestive of malignancy and found that sensitivity, specificity and positive predictive value of ultrasonography in suggesting a malignant lesion were 75,61 and $19 \%$, respectively. Sensitivity, specificity and positive predictive value of FNA cytology for thyroid cancer were, however, higher $(92,85$ and $41 \%$, respectively) in their study. According to Watters et al. [5] malignant lesions should be suspected when there is a solid and hypoechoic and nonhaloed lesion. However, a cystic component of $50 \%$ or less may be present. The sensitivity, specificity and positive predictive value for malignancy as observed by these authors were 74, 83 and $51 \%$, respectively. Lin et al. [20] observed that low echogenicity was significantly higher in malignant cases $(76.2 \%)$ than in benign cases $(23.8 \%, p<0.05)$ and concluded that low echogenicity on ultasonography carried a higher risk of malignancy. In a study by Pant et al. [8] a nodule with peripheral irregular cystic degeneration was considered to be consistent with neoplastic disease. In the present study, the neoplastic goiters as well as hyperplastic nodules showed solid texture in a significantly higher number of cases compared to colloid goiter. Further, the neoplastic goiters presented with solid nodules and homogeneous hypoechoic pattern in a significantly higher number of cases compared to nonneoplastic lesions as a whole $(\mathrm{p}<0.01)$. The histopathology reports were available in a limited number of cases in our study. The sensitivity and specificity of ultrasound-guided/aided FNA cytology for neoplastic lesions and overall diagnosis accuracy were $87.5,100$ and $88.6 \%$, respectively, in our material. The sensitivity of FNA for carcinoma was $83.3 \%$. Thus, ultrasonography not only helped in the detection of solitary nodules and selection of areas for FNA, it also correlated with cyto- 
logic interpretation in a majority of cases. However, ultrasonography cannot replace cytologic diagnosis as the specificity and positive predictive values are not sufficiently accurate.

\section{Acknowledgment}

The authors wish to thank Mr. Mohanan T. Nair for his secretarial help in preparation of the manuscript.

\section{References}

1 Mazzaferri EL: Thyroid cancer in thyroid nodules: Finding a needle in the haystack. Am J Med 1992;93: 359-362.

2 Gagneten CR, Roccatagliata G, Lowenstein A, Soto F, Soto R: The role of fine needle aspiration biopsy cytology in the evaluation of the clinically solitary thyroid nodule. Acta Cytol 1987;31:595-598.

3 Fitz-Patrik D, Navin JJ, Fukunaga BN: Fine needle aspiration biopsy of thyroid nodules: A diagnostic method that minimizes the need for surgery. Postgrad Med 1986;80:62-65.

4 Ananthakrishnan N, Rao KM, Narasimhan R, Veliath AJ: Problem and limitations with fine needle aspiration cytology of solitary thyroid nodules. Aust NZ J Surg 1990;60: 35-39.

5 Watters DAK, Ahuja AT, Evans RM, Chick W, King WW, Metreweli $\mathrm{C}, \mathrm{Li}$ AK: Role of ultrasound in the management of thyroid nodules. Am J Surg 1992;164:654-657.

6 Seya A, Oeda T, Terano T, Omura M, Tahara K, Nishikawa T, Tamura Y, Yoshida S: Comparative studies on fine-needle aspiration cytology with ultrasound scanning in the assessment of thyroid nodule. Jpn J Med 1990;29:478-480.

7 Al-Sayer HM, Bayliss AP, Krukowski ZH, Matheson NA: The limitations of ultrasound in thyroid swellings. J R Coll Surg Edinb 1986;31: 27-31.

8 Pant CS, Gupta RK, Das DK: Evaluation of solitary cold thyroid nodule using ultrasonography and fine needle aspiration cytology. Indian J Med Ultrasound 1986;3:31-35.
9 Gelderblom AJ, vd Hoek W, Lips PT, Risse EK, Meijer CJ: A study of importance of fine needle aspiration cytology in the diagnosis of solitary thyroid nodule. Neth J Med 1990; 36:13-18.

10 Jones AJ, Aitman TJ, Edmonds CJ, Burke M, Hudson E, Tellez M: Comparison of fine needle aspiration cytology, radioisotopic and ultrasound scanning in the management of thyroid nodules. Postgrad Med J 1990;66:914-917.

11 Kumar A, Ahuja MM, Chattopadhyay TK, Padhy AK, Gupta AK, Kapila K, Goel AK, Karmarker MG: Fine needle aspiration cytology, sonography and radionuclide scanning in solitary thyroid nodule. J Assoc Physicians India 1992;40: 302-306.

12 Rosen IB, Azadian A, Walfish PG, Salem S, Lansdown E, Bedard YC: Ultrasound-guided fine needle aspiration biopsy in the management of thyroid disease. Am J Surg 1993; 166:346-349.

13 Okamoto T, Yamashita T, Harasawa A, Kanamuro T, Aiba M, Kawakami M, Ito Y, Murakami M, Fujimoto Y, Ohara T: Test performances of three diagnostic procedures in evaluating thyroid nodules: Physical examination, ultrasonography and fine needle aspiration cytology. Endocr J 1994;41:243-247.

14 Cochand-Priollet B, Guillausseau PJ, Chagnon S, Hoang C, Guillausseau-Scholer C, Chanson P, Dahan H, Warnet A, Tran Ba Huy PT, Valleur P: The diagnostic value of fineneedle biopsy under ultrasonography in nonfunctional thyroid nodules: A prospective study comparing cytologic and histologic findings. Am J Med 1994;97:152-157.
15 Gimondo P, Messina G, Caratozzolo M, Tomei A: Role of ultrasonography-guided fine-needle biopsy in the selection for surgical treatment in thyroid diseases: Multicenter retrospective study of 5109 patients. Radiol Med (Torino) 1994;87:648652.

16 Antonelli A, Miccoli P, Ferdeghini M, Di-Coscio G, Alberti B, Iacconi P, Baldi V, Fallahi P, Baschieri L: Role of neck ultasonography in the follow-up of patients operated on for thyroid cancer. Thyroid 1995;5:2528.

17 Cohen M, Lubin E, Olsha M, Freeman JL, Fairmesser R: Treatment decisions in thyroid surgery based on ultrasonography. Isr J Med Sci 1996;32:1302-1305.

18 Rojeski MT, Gharib H: Nodular thyroid disease: Evaluation and management. N Engl J Med 1985; 313:428-436.

19 Hamberger J: Needle aspiration for thyroid nodule. Postgrad Med 1988; 84:61-66.

20 Lin JD, Hsueh C, Chan TC, Weng HF, Huang BY: Thyroid follicular neoplasms diagnosed by high-resolution ultrasonography with fine needle aspiration cytology. Acta $\mathrm{Cy}$ tol 1997;41:687-691.

21 Garretti L, Gallo N, Balma F, Durando $\mathrm{R}$, Palestini N, Suppo M: Integration of $\mathrm{B}$-mode and color Doppler ultrasonography in the preoperative diagnosis of thyroid lesions: Preliminary experience in 91 cases. Minerva Chir 1997;52:783788.

22 Mazzaferri E: Management of a solitary thyroid nodule. N Eng J Med 1993;328:553-559. 